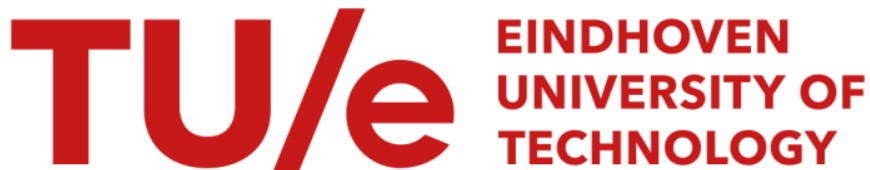

\section{Nonstoichiometry and electronic defects in yttrium iron garnet}

\author{
Citation for published version (APA): \\ Metselaar, R., \& Huyberts, M. A. H. (1977). Nonstoichiometry and electronic defects in yttrium iron garnet. \\ Journal of Solid State Chemistry, 22(3), 309-319. https://doi.org/10.1016/0022-4596\%2877\%2990007-X, \\ https://doi.org/10.1016/0022-4596(77)90007-X
}

DOI:

10.1016/0022-4596\%2877\%2990007-X

10.1016/0022-4596(77)90007-X

Document status and date:

Published: 01/01/1977

\section{Document Version:}

Publisher's PDF, also known as Version of Record (includes final page, issue and volume numbers)

\section{Please check the document version of this publication:}

- A submitted manuscript is the version of the article upon submission and before peer-review. There can be important differences between the submitted version and the official published version of record. People interested in the research are advised to contact the author for the final version of the publication, or visit the $\mathrm{DOI}$ to the publisher's website.

- The final author version and the galley proof are versions of the publication after peer review.

- The final published version features the final layout of the paper including the volume, issue and page numbers.

Link to publication

\section{General rights}

Copyright and moral rights for the publications made accessible in the public portal are retained by the authors and/or other copyright owners and it is a condition of accessing publications that users recognise and abide by the legal requirements associated with these rights.

- Users may download and print one copy of any publication from the public portal for the purpose of private study or research.

- You may not further distribute the material or use it for any profit-making activity or commercial gain

- You may freely distribute the URL identifying the publication in the public portal.

If the publication is distributed under the terms of Article 25fa of the Dutch Copyright Act, indicated by the "Taverne" license above, please follow below link for the End User Agreement:

www.tue.nl/taverne

Take down policy

If you believe that this document breaches copyright please contact us at:

openaccess@tue.nl

providing details and we will investigate your claim. 


\title{
Nonstoichiometry and Electronic Defects in Yttrium Iron Garnet
}

\author{
R. METSELAAR \\ Department of Physical Chemistry, Eindhoven University of Technology, Eindhoven, \\ The Netherlands
}

AND M. A. H. HUYBERTS

Philips Research Laboratories, Eindhoven, The Netherlands

Received February 18, 1977; in revised form May 12, 1977

\begin{abstract}
Results are presented of a thermogravimetrical analysis of yttrium iron garnet, $\mathrm{Y}_{3} \mathrm{Fe}_{5} \mathrm{O}_{12-\delta}$, in the temperature range $950-1270^{\circ} \mathrm{C}$. From these measurements the oxygen vacancy concentration $\delta$ is obtained for partial oxygen pressures between 1 and $10^{-5}$ atm. The data can be fitted with a relation $\delta-A$ $\exp (-E / k T)$. Values of $A$ and $E$ are given for different values of $P_{\mathrm{O}_{2}}$. The combined data from electrical conductivity measurements, measurements of Seebeck coefficients, and thermogravimetric analysis, are used to calculate the concentrations of point defects in the garnet lattice. The results are expressed in terms of equilibrium reaction constants. The model is also used to analyze diffusivity data.
\end{abstract}

The compound yttrium iron garnet (YIG), both pure and with various dopants, is of importance for applications in magnetic and in magneto-optic devices. It is found that some of its physical properties are influenced strongly by deviations from the stoichiometric composition. Measurements of magnetic susceptibility, lattice constant, optical absorption, and electrical conductivity $(1-3)$ have given information on the defects in this compound. In single crystals, which are grown from a leadbased flux, lead ions act as acceptors, while silicon impurities act as donors. Measurements at high temperature and varying oxygen pressure, both on single crystals and on polycrystalline samples, can be interpreted if it is assumed that oxygen vacancies are native defects. However, a quantitative knowledge of the vacancy concentration as a function of temperature and oxygen pressure is still lacking. We have therefore undertaken a study of the reversible oxygen loss by means of a sensitive thermobalance. In Section 1 the experimental setup is described, and in Section
2 the results of the thermogravimetric analysis (TGA) are presented. From earlier measurements of the electrical conductivity and the thermoelectric power as a function of temperature $T$ and partial oxygen pressure $P_{\mathrm{O}}$, information has been obtained on the density of states and on the position of energy levels (4). In Section 3 we calculate the concentration of point defects in a specific Ca-doped YIG sample as a function of $T$ and $P_{\mathrm{O}}$, using the combined data from electrical measurements and thermogravimetric analysis. From this calculation we derive equilibrium constants that can be used to compute defect concentrations in any sample of YIG with known amounts of acceptors and donors. Finally, in Section 4, we use the results of our calculations to re-examine oxygen diffusion data published previously (5).

\section{Experimental Details}

\subsection{Samples}

Since YIG single crystals are always contaminated with flux constituents, it seemed 
advantageous to use polycrystalline samples. The method of spray drying produces powders of very high purity (1). Pellets sintered from these spray-dried oxides did not show a second phase when investigated by means of X-ray diffraction or light microscopy of a polished sample. Nevertheless, small weight changes always occurred in TGA during the passage through the transition point $\mathrm{Fe}_{2} \mathrm{O}_{3} \leftrightarrows \mathrm{Fe}_{3} \mathrm{O}_{4}$. Because of this interference we decided to use single-crystalline samples instead. The measurements were performed on crystals grown from a $\mathrm{PbO}-\mathrm{PbF}_{2}-\mathrm{B}_{2} \mathrm{O}_{3}$ flux (3). At temperatures above about $1000^{\circ} \mathrm{C}$ an irreversible weight loss was observed. Similar changes were found for thin singlecrystalline iron garnet films, grown by liquid phase epitaxy on $\mathrm{Gd}_{3} \mathrm{Ga}_{5} \mathrm{O}_{12}$ substrates. There is much evidence that such films, which are grown from an undercooled melt, can contain appreciablc amounts of lead. During TGA of the films we observed a considerable irreversible weight loss. After many annealing treatments of different specimens, a light orange deposit was discovered near the specimen holder which, after chemical analysis, was identified as $\mathrm{PbO}(6)$. The lead concentration in the bulk crystals is less than in the films, so that a direct proof was impossible, but by analogy we assume that in this case, too, the irreversible weight losses are due to lead evaporation. Yet there is a large difference between the annealing behavior of films and bulk crystals. In the films nearly all lead can be removed by heat treatment. In the bulk crystals the total weight loss corresponds with about $0.002 \mathrm{~Pb}$ atoms per formula unit YIG $(0.2$ at\%). This is about the uncertainty in the chemical analysis for two different samples, and as a result we were unable to detect a change in the $\mathrm{Pb}$ content by a chemical analysis after annealing at $1400^{\circ} \mathrm{C}$ in oxygen for several days. For the TGA we used the annealed crystals, in which all weight changes were reversible. Though we could not reveal any flux inclusions by means of optical microscopy in our crystals, we cannot exclude the possibility that the irreversible weight loss was due to evaporation of lead atoms which were not dissolved in the lattice.

The first series of measurements were performed on a single crystal of Ca-doped yttrium iron garnet (sample 1). The analyzed impurity contents (in at\%) were: $\mathrm{Pb}, 2.0 \pm$ $0.2 ; \mathrm{Ca}, 1.7 \pm 0.2 ; \mathrm{Si}, 2.1 \pm 0.1$. Fluorine may be present in a concentration $<1 \% . \mathrm{Pb}$ and $\mathrm{Ca}$ were determined from atomic-absorption measurements; for $\mathrm{Si}$ and $\mathrm{F}$ a photometric analysis was used. A part of the crystal was used for electrical conductivity measurements (4). In accordance with the chemical analysis, the crystal shows $p$-type behavior. About 700 mg was used for TGA. For comparison we also performed a TGA on a nominally pure YIG crystal (sample 2). The analyzed impurity content in this sample is: $\mathrm{Pb}, 1.5 ; \mathrm{Ca}, 0.1 ; \mathrm{Si}$, $0.2 ; \mathrm{F}, 1.8$ at\%. Since the analysis in this case was not carried out on the powder used for TG $\Lambda$, but on a different crystal from the same batch, the uncertainty in the concentrations is higher than for sample 1 .

Due to the low oxygen diffusion rate the crystals had to be crushed into a fine powder. For this purpose we used a so-called electrohydraulic crusher (AERE Harwell). The apparatus makes use of a 50-kV spark discharge. A spectrochemical analysis of the powder showed the presence of traces of tantalum from the electrodes. However, the amount of Ta was too small to interfere with the TGA.

\subsection{Thermobalance}

The experiments were performed with the aid of a Setaram microbalance type MTB 108 . The balance has equal arms with a sample capacity of $10 \mathrm{~g}$ and a sensitivity of $0.4 \mu \mathrm{g}$. The balance proved to be relatively insensitive to vibrations, but quite sensitive to temperature fluctuations. Therefore the temperature in the room was controlled within $\pm 1^{\circ} \mathrm{C}$. The powdered sample was placed in an alumina crucible suspended in the hot zone with an alumina rod $0.5 \mathrm{~mm}$ in diameter (Fig. 1). A small hook was formed in each end of this rod by heating and bending. A $0.1-\mathrm{mm}$ Pt-10\% $\mathrm{Rh}$ wire attached to the balance arm was used 


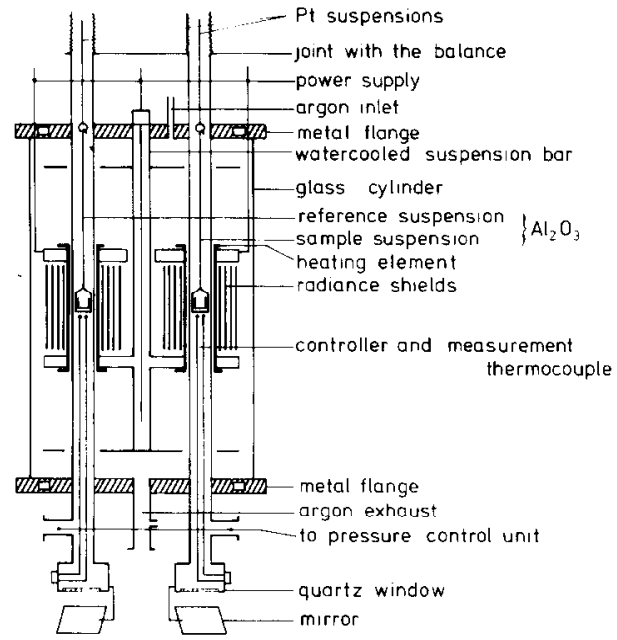

FIG. 1. Schematic drawing of the symmetrical furnace and of the sample suspension.

to support the alumina rod in the cold part of the furnace.

An identical arrangement was used on the reference arm of the symmetrical balance.

The balance is fitted with a symmetrical furnace (Setaram) which consists of two hexagonally shaped tungsten resistors. The furnace has very little thermal inertia; the maximum temperature of $1700^{\circ} \mathrm{C}$ can be reached in about $3 \mathrm{~min}$. The sample and the reference are isolated from the heating elements by means of gas tight alumina tubes, which have an internal diameter of $16 \mathrm{~mm}$. At about $1400^{\circ} \mathrm{C}$ the temperature in the hot zone of the furnace is found to be constant within $5^{\circ} \mathrm{C}$ over a range of $2 \mathrm{~cm}$. Some further details of the furnace construction are shown in Fig. 1.

Since the weight changes in the case of YIG are very small, we need a high sensitivity, and since the changes occur rather slowly, we also demand a very high stability over a long period. For this purpose we found it necessary to take a number of precautions. First, the temperatures of the sample and of the reference were controlled with calibrated Pt vs Pt-30\% Rh thermocouples, such that the temperature difference between sample and reference was $\angle 1^{\circ} \mathrm{C}$ under all circumstances. Second, the symmetrization of the loads on the two balance arms had to be as good as possible. Finally, the gas flow through the two furnace tubes had to be regulated carefully, with the aid of needle valves, in such a way that changes in flow or in gas composition did not lead to spurious weight changes. We shall consider the two last-mentioned points in more detail. A powdered sample with a weight of about $700 \mathrm{mg}$ was placed in an alumina crucible on one side of the balance. The weight on the reference side was adjusted within 10 $\mathrm{mg}$ with the aid of alumina. For further taring an electromagnetic taring module is available with the balance. However, to avoid adverse effects of the use of this electronic device on the long-term stability, we prefer further mechanical taring. This was performed within $1 \mathrm{mg}$ by placing platinum weights on plates which are fixed to the suspension hooks of the balance reference arm. To minimize apparent weight changes due to aerostatic thrust, viscous force caused by the gas flow, and thermomolecular forces, the total gas pressure, during most experiments, was reduced to 200 Torr, with a long-term stability of 0.05 Torr. For this purpose we used a suction-regulating valve (Negretti \& Zambra R 182N) modified such that the vacuum of a rotating oil pump is used as the reference pressure. The total gas flow was about $10 \mathrm{ml} / \mathrm{min}$ NTP.

With these precautions the maximum apparent weight changes in a blank run, for operation between 300 and $1700^{\circ} \mathrm{K}$, over periods of several weeks, were about $5-10 \mu \mathrm{g}$. Experiments at a constant temforature showed a long-term inaccuracy $<5 \mu \mathrm{g}$.

Using mixtures of oxygen and nitrogen the partial oxygen pressure near the sample could be regulated between 1 and $10^{-6}$ atm. The oxygen concentration was measured at the entrance and the exit of the flow system by means of zirconia oxygen gauges.

\subsection{Experimental Procedure}

The experiments were performed in two ways. For procedure I, the weight change was 
recorded at a constant partial oxygen pressure, as a function of temperature. After a temperature change at constant $P_{\mathrm{O}}$ the weight change of the YIG sample proceeded slowly, and moreover the total change was only a few micrograms. Under the circumstances, the highest accuracy was obtained by making a stepwise change in temperature, taking advantage of the quick furnace response, followed by a plateau of constant temperature until equilibrium was reached. We used step heights of $40^{\circ} \mathrm{C}$, and recorded the sample weight during $6 \mathrm{hr}$ between each step.

For procedure II, the weight change was recorded at a constant temperature as a function of the partial oxygen pressure. The furnace was adjusted at a constant temperature and $P_{\mathrm{O}_{2}}$ was lowered to about $10^{-5}$ atm. For the same reason as with procedure $I$, the pressure was now raised in steps, and after each step the weight change $\Delta \mathrm{g}$ was recorded until equilibrium was reached. The procedure was repeated at different temperatures. As can be seen from the preceding section procedure II has a higher experimental accuracy than procedure I.

\section{Results and Discussion}

The first experiment was performed using procedure I. The results of a complete heating and cooling cycle, at constant pressure $P_{\mathrm{O}_{2}}=1$ atm, are shown in Fig. 2. The results shown were obtained on a crushed single crystal of Ca-doped yttrium iron garnet (sample 1), with a total weight of $671 \mathrm{mg}$. The reversible weight change as a function of temperature is attributed to a loss (or gain) of oxygen, compensated by oxygen vacancies in the garnet lattice. To calculate the number of oxygen vacancies we assume that near $900^{\circ} \mathrm{C}$ at $P_{\mathrm{O}_{2}}=1$ atm, where the change of weight is below the detection limit, the garnet has the stoichiometric composition. A weight loss of $1 \mu \mathrm{g}$ for this sample means $\delta=6.8 \times 10^{-5}$, where $\delta$ is the number of oxygen vacancies in $\mathrm{Y}_{3} \mathrm{Fe}_{5} \mathrm{O}_{12-\delta}$. With this assumption we can translate weight changes in terms of the absolute vacancy concentration $\delta$, with an uncertainty of less than $7 \times 10^{-5}$.

Procedure II was used for the following experiments. Results were obtained at 12 different temperatures in the range 950$1270^{\circ} \mathrm{C}$. Figure 3 gives a survey of the experimental data. Apart from the number of vacancies, $\delta$, the vacancy concentration $\left[V_{0}\right]$ per $\mathrm{cm}^{3}$ is also given, where $\left[V_{\mathrm{o}}\right]=4.22 \times$ $10^{21} \delta \mathrm{cm}^{-3}$. From Figs. 2 and 3 it follows that the vacancy concentration at $P_{\mathrm{O}_{2}}=1$ atm increases with temperature to about $\delta=0.002$ near $1400^{\circ} \mathrm{C}$. A lowering of $P_{\mathrm{o}_{2}}$ causes an increase in $\delta$, as expected. It was found that at

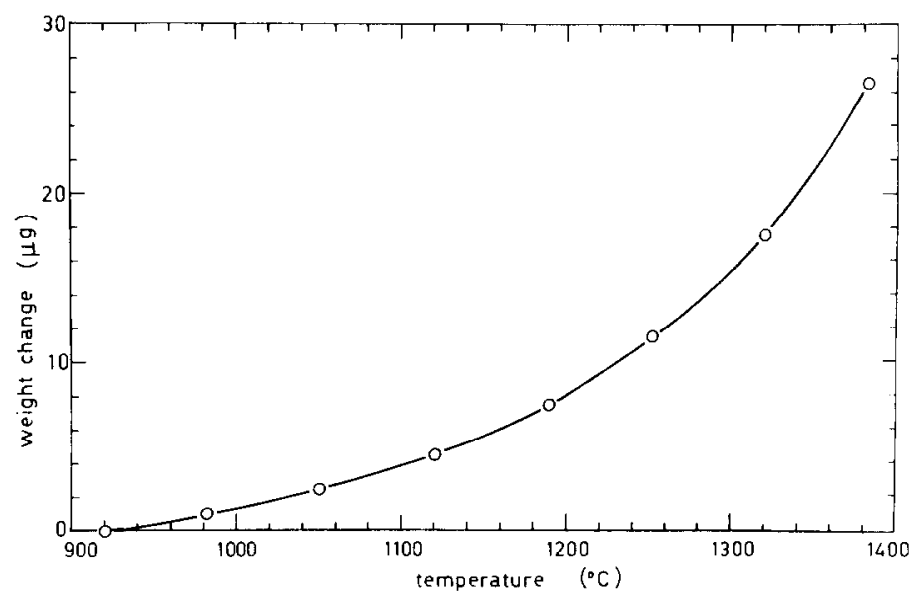

FIG. 2. Reversible weight change as a function of temperature at a partial oxygen pressure of 1 atm, of yttrium iron garnet. Total sample weight $671 \mathrm{mg}$. Analyzed impurity content 2 at $\% \mathrm{~Pb}, 1.7$ at $\% \mathrm{Ca}, 2.1$ at $\% \mathrm{Si}$. 


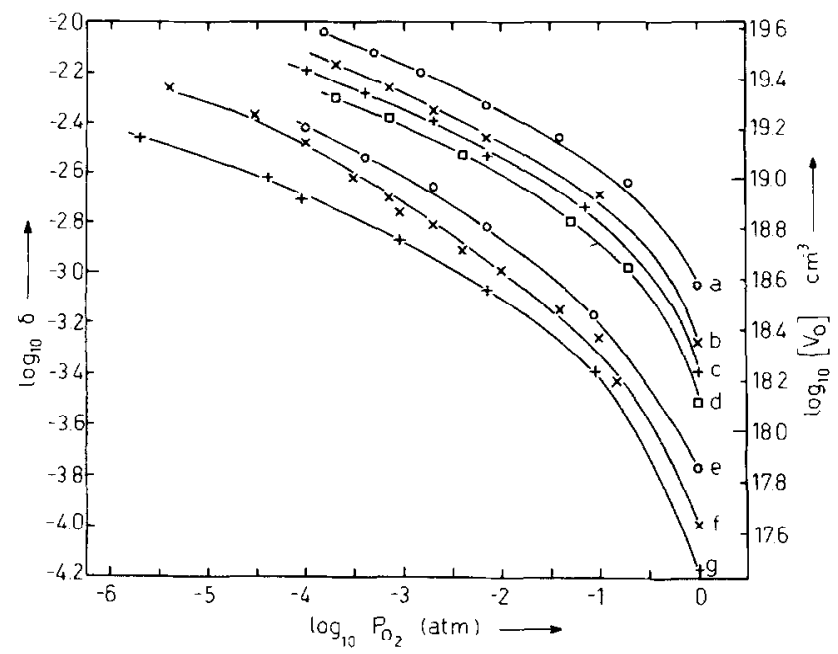

FIG. 3. Oxygen vacancy concentration as a function of partial oxygen pressure at different temperatures $\left({ }^{\circ} \mathrm{C}\right) ; \delta$ is the concentration in atoms per formula unit $\mathrm{Y}_{3} \mathrm{Fe}_{5} \mathrm{O}_{12},\left[V_{0}\right]$ is the concentration in $\mathrm{cm}^{-3}: \mathrm{a}=1268, \mathrm{~b}=1189$, $c=1157, d=1122, e=1055, f=993, g=951$.

$1270^{\circ} \mathrm{C}$ and at $P_{\mathrm{O}_{2}}<10^{-4}$ atm, the garnet decomposes. The maximum concentration of oxygen vacancies that can be accommodated in the garnet lattice seems to be about 0.01 per formula unit.

Figure 4 shows the measured vacancy concentration $\left[V_{0}\right]$ at different partial oxygen pressures, as a function of the reciprocal temperature. From the figure it follows that the data obey the relation

$$
\left[V_{\mathrm{o}}\right]=K_{0} \exp (-E / k T) \text {. }
$$

A least squares fit through the data points gives values of the constants $K_{0}$ and of the activation enthalpy $E$, as shown in Table I.

It should be noted, however, that these numbers apply only to the Ca-doped crystal (sample 1) investigated here. The total oxygen vacancy concentration depends largely upon the concentration difference between donors and acceptors. Indeed, slightly different results were obtained on sample 2 . The experimental data for the temperature range $900-1240^{\circ} \mathrm{C}$ are described again by Eq. (1). Values of the constants $K_{0}$ and $E$ are shown in Table I. It follows from these data that at $1100^{\circ} \mathrm{C}$ and $P_{\mathrm{O}_{2}}=0.1 \mathrm{~atm}$, sample 1 has a vacancy concentration $\left[V_{0}\right]=2.2 \times 10^{19} \mathrm{~cm}^{-3}$, while in sample $2\left[V_{\mathrm{o}}\right]=1.5 \times 10^{19} \mathrm{~cm}^{-3}$.
Summarizing, we have determined the oxygen vacancy concentration, as a function of

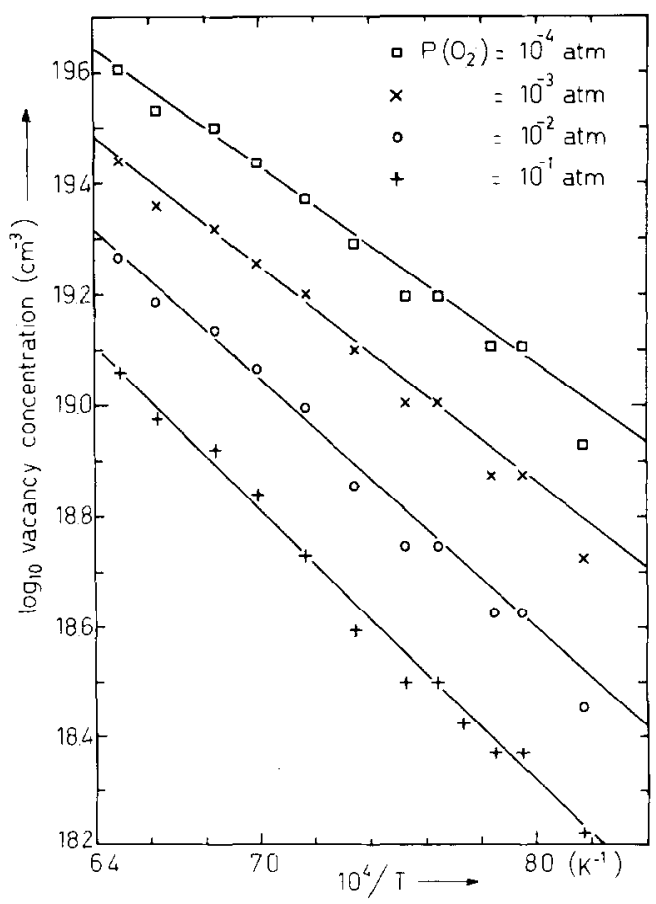

FIG. 4. The logarithm of the oxygen vacancy concentration $\left|V_{0}\right|$ in $\mathrm{cm}^{-3}$ as a function of the reciprocal temperature, at four different values of the partial oxygen pressure. 
TABLE I

Values of the Constants $K_{0}$ And $E$ (EQ. 1$)^{a}$

\begin{tabular}{ccccccc}
\hline & \multicolumn{2}{c}{ Sample 1} & & \multicolumn{2}{c}{ Sample 2 } \\
\cline { 5 - 7 } $\begin{array}{c}\text { Partial oxygen } \\
\text { pressure (atm) }\end{array}$ & $K_{0}\left(\mathrm{~cm}^{-3}\right)$ & $E(\mathrm{eV})$ & & $K_{0}\left(\mathrm{~cm}^{-3}\right)$ & $E(\mathrm{eV})$ \\
\hline $10^{-1}$ & $1.82 \times 10^{22}$ & 0.98 & & & $5.36 \times 10^{21}$ & 0.85 \\
$10^{-2}$ & $1.54 \times 10^{22}$ & 0.89 & & $9.06 \times 10^{20}$ & 0.58 \\
$10^{-3}$ & $8.92 \times 10^{21}$ & 0.77 & & $3.43 \times 10^{20}$ & 0.41 \\
$10^{-4}$ & $8.00 \times 10^{21}$ & 0.70 & & $2.52 \times 10^{20}$ & 0.33 \\
\hline
\end{tabular}

${ }^{a}$ Determined from a thermogravimetric analysis of Ca-doped YIG (sample 1) and undoped YIG (sample 2).

$P_{\mathrm{o}_{2}}$ and $T$, of yttrium iron garnet with a known concentration of impurities.

In the next section we shall combine these data with the results from electrical conductivity measurements, for a model calculation of the defect concentrations in YIG.

\section{Calculation of Defect Concentrations}

From measurements of electrical conductivity and thermoelectric power it was concluded that the charge carriers in both $n$-type and $p$-type YIG are described best as large polarons (4). Using the atomic notation of Kröger and Vink, the equilibrium reaction equations can be written as:

$$
\begin{aligned}
& \mathrm{O}_{\mathrm{O}} \rightleftharpoons \frac{1}{2}\left(\mathrm{O}_{2}\right)_{\text {gas }}+V_{\mathrm{O}}^{x}, \quad K_{p}=\left[V_{\mathrm{O}}^{x}\right] P_{\mathrm{O}_{2}}^{1 / 2} ; \\
& V_{0}^{x}=\dot{V_{\mathrm{O}}}+e^{\prime}, \quad K_{1}=n\left[\dot{V_{0}}\right] /\left[V_{0}^{x}\right] \text {; } \\
& V_{\mathrm{o}}^{*} \rightleftharpoons \ddot{V_{\mathrm{O}}^{*}}+e^{\prime}, \quad K_{2}=n\left[\ddot{V_{\mathrm{u}}}\right] /\left[V_{\mathrm{o}}^{*}\right] ; \\
& \mathrm{Si}^{x} \rightleftharpoons \mathrm{Si}^{*}+e^{\prime}, \quad K_{\mathrm{D}}=n\left[\mathrm{Si}^{*}\right] /\left[\mathrm{Si}^{x}\right] ; \\
& A^{x} \rightleftharpoons A^{\prime}+h, \quad K_{\mathrm{A}}-p\left[A^{\prime}\right] /\left[A^{x}\right] ; \\
& e^{\prime}+\dot{h} \rightleftharpoons \text { vacuum, } \quad K_{i}=n p \text {. }
\end{aligned}
$$

It is asssumed that besides oxygen vacancies, silicon ions are the only donors present. $[A]$ is used for the concentration of acceptor-type impurities. In our experiments we have used $\mathrm{Ca}$ or $\mathrm{Zn}$ acceptors, while $\mathrm{Pb}$ impurities are also present. Apart from Eqs. (2)-(7) we have the electroneutrality equation:

$$
n+\left[A^{\prime}\right]=p+[\mathrm{Si}]+\left[\ddot{V_{\mathrm{O}}^{*}}\right]+2\left[V_{\mathrm{o}}^{\ddot{*}}\right]
$$

In Eq. (8) all concentrations can be expressed in terms of density of states, ionization energies, and the Fermi energy $E_{\mathrm{F}}(7)$. We shall describe shortly the way in which the input parameters were obtained.

(a) The concentration of holes is given by $p=N_{+} \exp \left[-\left(E_{\mathrm{F}}-E_{\mathrm{v}}\right) / k T\right]$, the concentration of electrons by $n=N_{-} \exp \left[-\left(E_{\mathrm{c}}-E_{\mathrm{F}}\right) / k T\right]$. Here $N$ denotes the density of states. From measurements of electrical conductivity and Seebeck coefficients in YIG samples with different concentrations of acceptors and donors (4) we derive $N_{+} \mu_{+} e^{A_{+}}=3.0 \times 10^{21}(\mathrm{~V}$ $\mathrm{sec} \mathrm{cm})^{-1}, N_{-} \mu_{-} e^{A}=5.2 \times 10^{20}(\mathrm{~V} \mathrm{sec} \mathrm{cm})^{-1}$. Here $\mu$ is the mobility and $A$ is the transport constant. The subscripts + and - indicate holes and electrons, respectively. If we assume that the charge transport in YIG is due to large polarons, we obtain the data given in Table II.

TABLE II

Density of States $N_{ \pm}$, Mobility $\mu_{ \pm}$, AND Transport Constant $A_{ \pm}$for Holes $(+)$and ELECTRONS (-) ${ }^{a}$

\begin{tabular}{cc}
\hline$N_{+}\left(\mathrm{cm}^{-3}\right)$ & $4.74 \times 10^{15} T^{3 / 2}$ \\
$\mu_{+}\left(\mathrm{cm}^{2} \mathrm{~V}^{-1} \mathrm{sec}^{-1}\right)$ & $8.4 \times 10^{4} T^{-3 / 2}$ \\
$A_{+}$ & 2 \\
$N_{-}\left(\mathrm{cm}^{-3}\right)$ & $1.45 \times 10^{16} T^{3 / 2}$ \\
$\mu_{-}\left(\mathrm{cm}^{2} \mathrm{~V}^{-1} \mathrm{sec}^{-1}\right)$ & $4.8 \times 10^{3} T^{-3 / 2}$ \\
$A_{-}$ & 2 \\
$E_{v}(\mathrm{eV})$ & 0 \\
$E_{\mathrm{c}}(\mathrm{cV})$ & $2.85-8 \times 10^{-4} \mathrm{~T}$ \\
\hline
\end{tabular}

${ }^{a}$ Energy of the valence band $E_{\mathrm{v}}$ and of the conduction band, $E_{\mathrm{c}}$. 


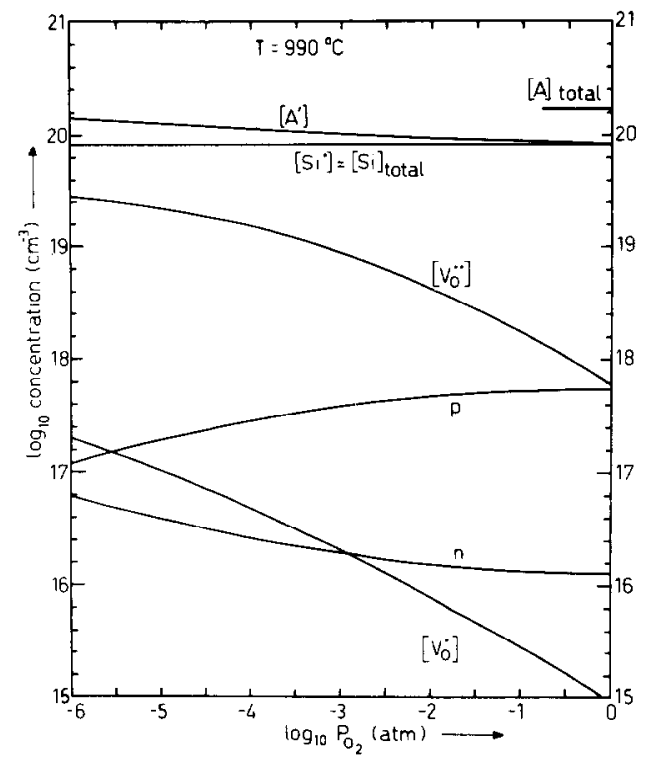

FIG. 5. Calculated defect concentrations in Ca-doped YIG at $990^{\circ} \mathrm{C}$ as a function of the partial oxygen pressure. $A$ denotes $\mathrm{Ca}$ and $\mathrm{Pb}$ acceptors.

The top of the valence band is set cqual to $E_{\mathrm{v}}$ $=0$, while the bottom of the conduction band is given by $E_{\mathrm{c}}=2.85-8 \times 10^{-4} \mathrm{TeV}$.

(b) The concentration of ionized silicon donors is calculated from $\left[\mathrm{Si}{ }^{\circ}\right]=[\mathrm{Si}]_{\text {total }}\{1+2$ $\left.\exp \left[-\left(E_{\mathrm{Si}}-E_{\mathrm{F}}\right) / k T\right]\right\}^{-1}$, and a similar expression holds for the acceptors. The total concentration of the donors $[\mathrm{Si}]_{\text {total }}$, and of the acceptors $[\mathrm{Ca}]_{\text {total }},[\mathrm{Pb}]_{\text {total }}$ is known from a chemical analysis. We obtain $[\mathrm{Si}]_{\text {total }}=8.6 \times$ $10^{19} \mathrm{~cm}^{-3},[\mathrm{Ca}]_{\text {total }}=7.2 \times 10^{19} \mathrm{~cm}^{-3}$, $[\mathrm{Pb}]_{\text {total }}=8.5 \times 10^{19} \mathrm{~cm}^{-3}$. For the ionization energy of silicon Ref. (4) gives $0.3 \mathrm{eV}$. The ionization energies of $\mathrm{Ca}$ and $\mathrm{Pb}$ are not accurately known. From the conductivity measurements we estimate $E_{\mathrm{Ca}} \approx E_{\mathrm{Pb}} \approx 0.5-$ $0.7 \mathrm{eV}$.

(c) The concentration of ionized oxygen vacancies is a function of the total vacancy concentration, $\left[V_{0}\right]$, of the ionization energy of a neutral vacancy $\left(E_{\mathrm{c}}-E_{V_{\mathrm{o}}}\right)$, and of the ionization energy of a singly ionized vacancy, $\left(E_{\mathrm{c}}-E_{V_{\mathrm{o}}}\right)$. The formulas are given in the appendix, Eqs. (Al) and (A2). The constants in these expressions are derived from the thermo- gravimetric analysis and from conductivity measurements on the same Ca-doped YIG sample. From the TGA we obtained the total concentration of oxygen vacancies $\left[V_{0}\right]$ as a function of temperature and partial oxygen pressure (Eq. 1). The energy level of the neutral oxygen vacancies, $E_{V_{0}}$, is probably close to the conduction band. We assume an ionization energy of $0.1 \mathrm{eV}$, but the real value is not critical for the calculation. From measurements of space-charge-limited currents in YIG (8) we infer an ionization energy of $0.85 \mathrm{eV}$ at $300^{\circ} \mathrm{K}$ for the singly ionized oxygen vacancies, $V_{\mathrm{o}^{*}}$. The temperature dependence is unknown, however, and the value of $\left(E_{\mathrm{c}}-E_{V_{0}}\right)$ is probably less at $1300^{\circ} \mathrm{K}$. Therefore $E_{V_{0}^{\circ}}^{0}$ is treated as a variable.

The calculation of the defect concentrations was performed in a number of discrete steps.

Step 1. Using the known values of $K_{0}$ and $E_{0}$ at a fixed pressure, e.g., $P_{\mathrm{o}_{2}}=0.01 \mathrm{~atm}$, and with trial values for $E_{\mathrm{Ca}}$ and ${ }^{2} E_{v_{u^{*}}}$ Eq. (8) was solved for $E_{\mathbf{F}}$.

Step 2. From $E_{\mathrm{F}}$ we obtained $\left[V_{\mathrm{o}}^{x}\right]$ at the given pressure as a function of temperature. With this $K_{p}$ was fixed, and next from $K_{p}$ we could calculate $\left[V_{\mathrm{O}}^{x}\right]$ at any value of $T$ and $P_{\mathrm{O}_{2}}$.

Step 3. Using Eqs. (A3) and (A4), $E_{\mathrm{F}}$ was calculated from Eq. (8) as a function of $T$ and $P_{\mathrm{o}}$. From $E_{\mathrm{F}}$ all defect concentrations were obtained. The total vacancy concentration $\left[V_{\mathrm{o}}\right]=\left[V_{\mathrm{o}}^{x}\right]+\left[V_{\mathrm{o}}^{\dot{0}}\right]+\left[V_{\mathrm{o}}^{\ddot{*}}\right]$ was compared with the experimental results from the TGA. From the calculated $n$ and $p$ values we obtained the electrical conductivity and Seebeck coefficient as a function of $T$ and $P_{\mathrm{O}_{2}}$. These values were compared with the experimental results (4). By trial and error we obtained the best fit with the experimental data if we assumed for the acceptor level $E_{\mathrm{A}}=0.57$ $\mathrm{eV}$, and for the vacancy level $E_{V_{0}}=E_{\mathrm{c}}-$ $0.4 \mathrm{eV}$ in the temperature region $900-1300^{\circ} \mathrm{C}$. The calculated defect concentrations at $990^{\circ} \mathrm{C}$, in the Ca-doped YIG crystal (sample 1 of (4)), are shown in Fig. 5. The silicon donors are fully ionized, $\left[\mathrm{Si}^{\circ}\right]=[\mathrm{Si}]_{\text {total }}$. At $P_{\mathrm{O}_{2}}$ 
TABLE III

Calculated Values of the Equilibrium Constants Defined IN EQS. (2)-(7) (SeE TeXT) ${ }^{a}$

$$
\begin{aligned}
& K_{p}=3.99 \times 10^{32} P_{\mathrm{O}_{2}}^{1 / 2} \exp (-5.58 / k T) \mathrm{cm}^{-3} \mathrm{~atm}^{1 / 2} \\
& K_{1}=6.69 \times 10^{21} \exp (-0.28 / k T) \mathrm{cm}^{-3} \\
& K_{2}=1.62 \times 10^{21} \exp (-0.58 / k T) \mathrm{cm}^{-3} \\
& K_{\mathrm{D}}=1.60 \times 10^{21} \exp (-0.47 / k T) \mathrm{cm}^{-3} \\
& K_{\mathrm{A}}=5.5310^{20} \exp (-0.75 / k T) \mathrm{cm}^{-3} \\
& K_{i}=7.41 \times 10^{35} T^{3} \exp (-2.85 / k T) \mathrm{cm}^{-6}
\end{aligned}
$$

${ }^{a}$ Activation energies in $\mathrm{eV}$.

$=10^{-6} \mathrm{~atm}$ the electroneutrality equation can be simplified to $\left[A^{\prime}\right]=2\left[V_{0}^{* \prime}\right]+\left[\mathrm{Si}_{\text {total }}\right.$. With increasing oxygen pressure the concentration of oxygen vacancies decreases, while the concentration of holes increases, until at about $1 \mathrm{~atm} p$ and $\left[\overrightarrow{V_{\mathrm{o}}}\right]$ are approximately equal. If we express the concentrations in units of $10^{17}$ $\mathrm{cm}^{-3}$, we can write Eq. (8), at $990^{\circ} \mathrm{C}$ and $P_{\mathrm{O}_{2}}$ $=1 \mathrm{~atm}$, as

$$
0.13+857=5.61+839+0.009+12.26 \text {. }
$$

The resulting values of the equilibrium constants, defined in Eqs. (2)-(7), are given in Table III.
In Fig. 6 the calculated total oxygen vacancy concentration, $\left[V_{0}\right]=\left[V_{0}^{x}\right]+\left[V_{0}^{j}\right]+$ $\left[V_{0}^{*}\right]$, is indicated by the solid line. The line fits closely to the TGA data points at four different temperatures. Only at $1 \mathrm{~atm}$ are the calculated values higher than the experimental ones. However, at this pressure the experimental values have the highest inaccuracy, and may be systematically too low. From Fig. 5 and Eq. $\left(8^{\prime}\right)$ it is seen that the total vacancy concentration can be approximated by $\left[V_{0}\right]=$ $\left[V_{\mathrm{o}}^{*}\right]$. This is the case for the entire temperature region $1000-1300^{\circ} \mathrm{C}$ and for partial oxygen pressures in the range $10^{-6}-1$ atm.

From the calculations we obtain values for the electrical conductivity and the thermoelectric power. Results for the Ca-doped YIG sample are shown in Figs. 7 and 8. The solid line in Fig. 7 denotes the experimentally determined values of the logarithm of the resistivity $\rho$ vs $T^{-1}$. The circles are the calculated $\rho$ values. The dashed line gives the experimentally determined values of the reduced Seebeck coefficients $a^{\prime}=a e / k \ln 10$ (cf. (4)), while the squares are calculated $\alpha^{\prime}$ values. Figure 8 shows the conductivity of the same sample, at $990^{\circ} \mathrm{C}$, as a function of the partial oxygen pressure. In view of the experimental

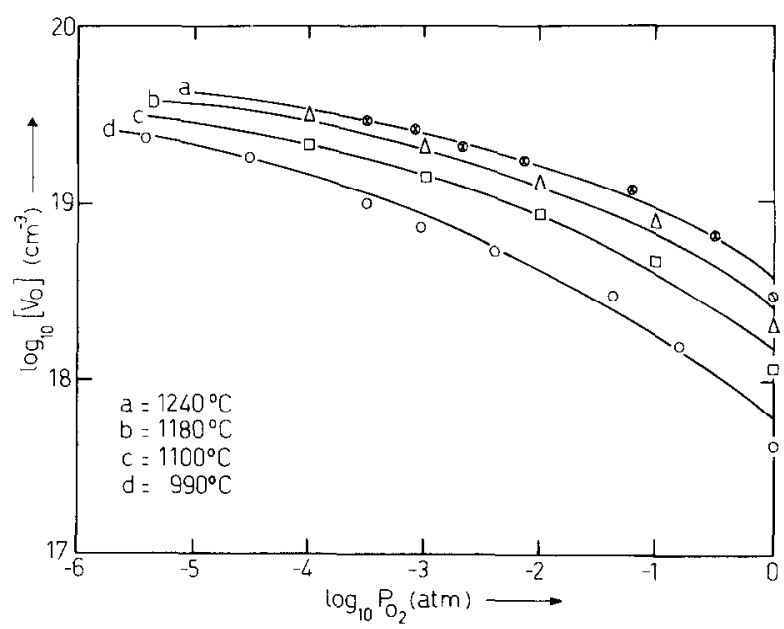

FIG. 6. Solid lines give the calculated total concentration of oxygen vacancies as a function of the partial oxygen pressure at different temperatures. The points are experimental data obtained from thermogravimetric analysis. The experimental values at $P_{\mathrm{O}_{2}}=10^{-2}$ atm have been used as a starting point for the calculations. 


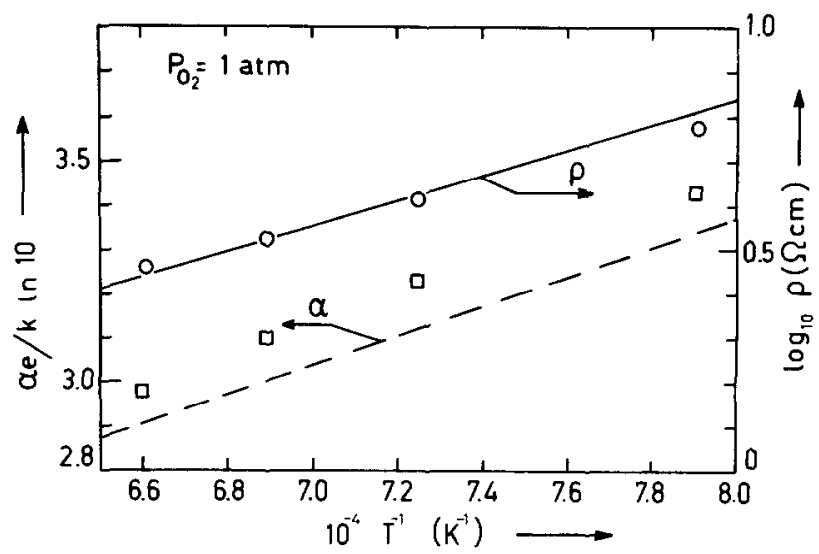

FIG. 7. Solid line: experimental values of the logarithm of the resistivity $\rho$ of Ca-doped YIG as a function of the reciprocal temperature, at $P_{\mathrm{O}_{2}}=1 \mathrm{~atm}$. Circles: calculated $\rho$ values. Dashed line: experimental values of the reduced Seebeck coefficient $\varpi e / k \ln 10$ vs the reciprocal temperature. Squares: calculated reduced Seebeck coefficients.

inaccuracy and of the uncertainties in the input parameters used for the computation, we do not think that a further optimization is justified.

From the calculations for the Ca-doped sample we have obtained the positions of the energy levels and the value of $K_{p}$. Next we can use the model to calculate the defect concentrations in YIG samples with different dopant concentrations. As an example we investi-

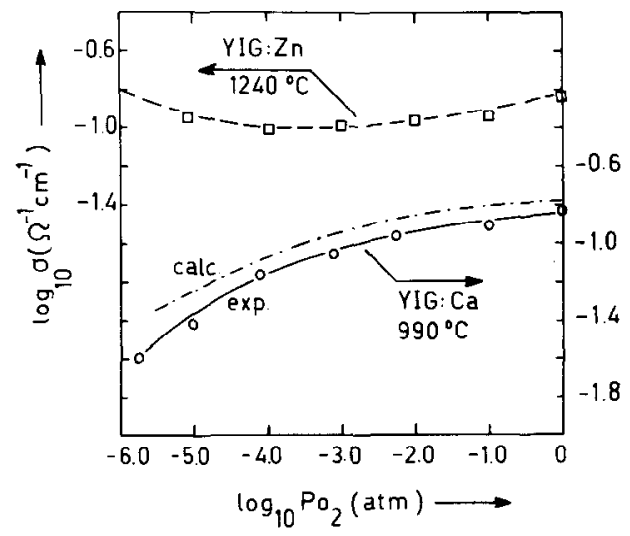

FlG. 8. Electrical conductivity as a function of the partial oxygen pressure: $\mathrm{O}$, experimental data for $\mathrm{Ca}$ doped YIG at $990^{\circ} \mathrm{C} ;-\cdots$, calculated values; $\square$, experimental data for $\mathrm{Zn}$-doped YIG at $1240^{\circ} \mathrm{C}$; --, calculated values. gated silicon-doped YIG. The analyzed impurity content was $[\mathrm{Si}]=3.5 \times 10^{20} \mathrm{~cm}^{-3}$, $[\mathrm{Pb}]=1.7 \times 10^{20} \mathrm{~cm}^{-3}$. From our calculations we find that in this case Eq. (8) can be simplified to $n=\left[\mathrm{SI}^{\circ}\right]-[A]_{\text {total }}$. For instance, at $T=1000^{\circ} \mathrm{C}$ and $P_{\mathrm{O}_{2}}=1 \mathrm{~atm}$, the neutrality equation, expressed in units of $10^{17} \mathrm{~cm}^{-3}$, is

$$
\begin{gathered}
179+1700=4 \times 10^{-3}+1880+7 \times 10^{-6}+ \\
6 \times 10^{-6} .
\end{gathered}
$$

At this temperature the total oxygen vacancy concentration is $1 \times 10^{11} \mathrm{~cm}^{-3}$ at $P_{\mathrm{O}_{2}}=1 \mathrm{~atm}$, and $1 \times 10^{15} \mathrm{~cm}^{-3}$ at $P_{\mathrm{o}_{2}}=10^{-6} \mathrm{~atm}$, which is too low to be measured in our TGA experiments. In accordance with our calculation we found that also the electrical conductivity is unaffected by a change in $P_{0}$. In the temperature range $1000-1300^{\circ} \mathrm{C}$ both the $\log \rho$ vs $T^{-1}$ and the $\alpha^{\prime}$ vs $T^{-1}$ curves are somewhat above the experimentally determined curves. For instance, at $1000^{\circ} \mathrm{C}$ one has $\log \rho$ (calc) $=$ $0.50, \alpha^{\prime}($ calc $)=2.42$, while $\log \rho(\exp )=0.34$ and $a^{\prime}(\exp )=2.24$. The position of the curves, however, is very sensitive to the donor and acceptor concentrations, both of which are not accurately known. Further, in this case the Fermi level is close to the silicon level, and a small change in $E_{\mathrm{Si}}$ strongly influences the defect concentrations. Therefore, we conclude 
that the model presented above gives a satis factory description of the defect concentrations in yttrium iron garnet.

\section{Implications of the Model Calculations for the Interpretation of Diffusivity Measurements}

In an earlier publication (5) we described the use of dynamic conductivity measurements for the determination of oxygen vacancy diffusion in YIG. The assumption made in the abovementioned study was that the electrical conductivity depends linearly on the vacancy concentration. It was also assumed that the diffusion is determined by one type of oxygen vacancies only. The more detailed knowledge now available enables us to reinvestigate the diffusivity results. Since most of the diffusion measurements were performed on a single crystal containing $\mathrm{Pb}$ and $\mathrm{Zn}$ as major acceptors, we have calculated the defect concentration of this sample as a function of temperature and partial oxygen pressure. By adjusting the $\mathrm{Zn}$ level until the best agreement between experimental and calculated conductivity was obtained, we found $E_{\mathrm{zn}}=1.0 \mathrm{eV}$. Figure 8 shows the calculated and measured conductivity values at $1240^{\circ} \mathrm{C}$ as a function of the partial oxygen pressure. From the calculated values of the defect concentrations we

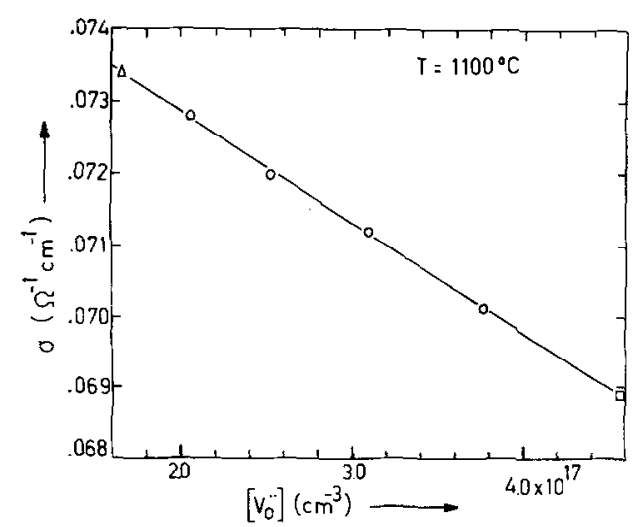

FIG. 9. Relation between the conductivity $\sigma$ at $1100^{\circ} \mathrm{C}$ of $\mathrm{Zn}$ doped YIG, and the concentration of doubly ionized oxygen vacancies $\left[\boldsymbol{V}_{o}^{*}\right]$, upon a variation of the partial oxygen pressure. Triangle at the left-hand side, $P_{\mathrm{O}_{2}}=1$ atm, square at the right-hand side, $P_{\mathrm{O}_{2}}=0.1$ atm. can draw some important conclusions. In the first place we found that in the temperature range $900-1300^{\circ} \mathrm{C}$ the ratio $\left[V_{\mathrm{o}}^{*}\right] /\left[V_{\mathrm{o}}\right]$ decreases from about 4000 to 20 . This means that $V_{\mathrm{o}}^{\ddot{*}}$ is the major defect throughout the entire temperature range used for the diffusion measurements. Next, in Fig. 9 we have plotted $\sigma$ vs $\left[V_{0}^{\prime \prime}\right]$ at $1100^{\circ} \mathrm{C}$ in the $P_{0}$, pressure range 1 to $0.1 \mathrm{~atm}$. It can be seen that the points are sufficiently close to a straight line to justify our initial supposition that $\sigma \propto\left[V_{0}^{*}\right]$. This also means that the ambipolar diffusion coefficient $\tilde{D}_{\mathrm{v}}$ of the oxygen vacancies is determined by the diffusion of three kind of charged particles, viz., $V_{\mathrm{o}}$, electrons, and holes. If we designate the respective particle diffusion coefficients with $D_{\mathrm{v}}, D_{\mathrm{e}}, D_{\mathrm{h}}$, we find

$$
\begin{aligned}
\tilde{D}_{\mathrm{v}} & =D_{\mathrm{v}}\left(1-2\left[\ddot{V_{\mathrm{o}}}\right]\right. \\
& \left.\times \frac{-D_{\mathrm{e}}\left(\delta n / \delta\left[\ddot{V_{\mathrm{o}}}\right]\right)+D_{\mathrm{h}}\left(\delta p / \delta\left[\ddot{V_{\mathrm{o}}}\right]\right)+2 D_{\mathrm{v}}}{D_{\mathrm{e}} n+D_{\mathrm{h}} p+4 D_{\mathrm{v}}\left[\ddot{V_{\mathrm{o}}}\right]}\right) .
\end{aligned}
$$

Near $1100^{\circ} \mathrm{C}$ we have $\mu_{\mathrm{e}} \approx 0.1 \mathrm{~cm}^{2} / \mathrm{V} \mathrm{sec}$ and $\mu_{\mathrm{h}} \approx 1 \mathrm{~cm}^{2} / \mathrm{V}$ sec. Using the Nernst-Einstein equation we get $D_{\mathrm{e}} \sim 10^{-2} \mathrm{~cm}^{2} / \mathrm{sec}$ and $D_{\mathrm{h}} \approx$ $10^{-1} \mathrm{~cm}^{2} / \mathrm{sec}$. Since $\tilde{D}_{\mathrm{v}} \approx D_{\mathrm{v}} \approx 10^{-7} \mathrm{~cm}^{2} / \mathrm{sec}$ and $n \approx p \approx\left[\ddot{V_{\mathrm{o}}}\right]$, Eq. (9) can be simplified to

$$
\tilde{D}_{\mathrm{v}}=D_{\mathrm{v}}\left[1-2\left(\delta \ln p / \delta \ln V_{\mathrm{o}}^{*}\right)\right] \text {. }
$$

The correction factor $\tilde{D_{v}} / D_{v}$ can be calculated as a function of temperature with the use of our model. It was found that $\tilde{D}_{\mathrm{v}} / D_{\mathrm{v}}$ increases from 1.01 at $900^{\circ} \mathrm{C}$ to 1.65 at $1300^{\circ} \mathrm{C}$.

In (5) the experimental diffusion data were described by $\tilde{D}_{\mathrm{v}}=\tilde{A} \exp (-\tilde{Q} / k T)$, with $\tilde{A}=$ $8400 \mathrm{~cm}^{2} / \mathrm{sec}$, and $\tilde{Q}=2.90 \mathrm{eV}$. It was assumed that $\tilde{D_{\mathrm{v}}} \approx D_{\mathrm{v}}$, and consequently the activation enthalpy of $2.90 \mathrm{eV}$ was identified with the migration enthalpy of the oxygen vacancies. The present calculation shows that the necessary correction is indeed small. If the experimentally obtained values of $\tilde{D}_{\mathrm{y}}$ are converted to $D_{v}$, with the aid of Eq. (10), we get $D_{\mathrm{v}}=A \exp (-Q / k T)$, with $A=1000$ $\mathrm{cm}^{2} / \mathrm{sec}$ and $Q=2.70 \pm 0.10 \mathrm{eV}$. The analysis given above therefore strongly supports the conclusions of $(5)$. 


\section{Appendix}

The concentration of ionized oxygen vacancies can be written as

$$
\begin{gathered}
{\left[V_{\mathrm{o}}^{*}\right]=\frac{2\left[V_{\mathrm{o}}\right] \exp \left(\left(E_{V_{\mathrm{o}}}-E_{\mathrm{F}}\right) / k T\right)}{\left\{\begin{array}{c}
1+\exp \left(\left(E_{V_{\mathrm{o}}}+E_{V_{\mathrm{o}}}-2 E_{\mathrm{F}}\right) / k T\right) \\
+2 \exp \left(\left(E_{V_{\mathrm{o}}}-E_{\mathrm{F}}\right) / k T\right)
\end{array}\right\}}} \\
{\left[\ddot{V_{\mathrm{o}}}\right]=\frac{\left[V_{\mathrm{o}}\right] \exp \left(\left(E_{V_{\mathrm{o}}}+E_{V_{\mathrm{o}}}-2 E_{\mathrm{F}}\right) / k T\right)}{\left\{\begin{array}{c}
1+\exp \left(\left(E_{V_{\mathrm{o}}}+E_{V_{\mathrm{o}}}-2 E_{\mathrm{F}}\right) / k T\right) \\
+2 \exp \left(\left(E_{V_{\mathrm{o}}}-E_{\mathrm{F}}\right) / k T\right)
\end{array}\right\}}}
\end{gathered}
$$

Instead of the total oxygen vacancy concentration, $\left[V_{\mathrm{o}}\right]$, we can also use the concentration of neutral vacancies, $\left[V_{0}^{x}\right]$ :

$$
\begin{gathered}
{\left[V_{\mathrm{o}}^{\cdot}\right]=2\left[V_{\mathrm{o}}^{x}\right] \exp \left(\left(E_{V_{\mathrm{o}}}-E_{\mathrm{F}}\right) / k T\right),(\mathrm{A} 3)} \\
{\left[\ddot{V_{\mathrm{o}}}\right]=\left[V_{\mathrm{o}}^{x}\right] \exp \left(\left(E_{V_{\mathrm{o}}}+E_{V_{\mathrm{o}}}-2 E_{\mathrm{F}}\right) / k T\right) .}
\end{gathered}
$$

\section{Acknowledgments}

The author wishes to thank his former colleagues from Philips Research Laboratories for discussions and for the reading of the manuscript.

\section{References}

1. R. Metselaar and M. A. H. Huyberts, J. Phys. Chem. Solids 34, 2257 (1973).

2. P. K. Larsen and R. Metselaar, J. Solid State Chem. 12, 253 (1975).

3. R. Metselaar and P. K. Larsen, J. Phys. Chem. Solids 37, 599 (1976).

4. P. K. Larsen and R. Metselaar, Phys. Rev. $B$ 14, 2520 (1976).

5. R. Metselaar and P. K. L arsen, $J$. Phys. Chem. Solids 34, 2257 (1973).

6. W. T. Stacy, M. A. H. Huyberts, R. Metselaar, AND A. B. VoERMANS, to appear.

7. J. S. Blakemore, Semiconductor Statistics, Pergamon, Oxford, 1962.

8. P. K. Larsen and R. Metselaar, Phys. Rev. B 8, 2016 (1973). 